Online Supporting Figures and Tables for

\title{
Universal Solid-phase Reversible Sample-Prep for Concurrent Proteome and $\mathrm{N}$-glycome Characterization
}

Hui Zhou, Samantha Morley, Stephen Kostel, Michael R. Freeman, Vivek Joshi, David Brewster, Richard S. Lee

Correspondence should be addressed to:

Richard S. Lee, MD

Boston Children's Hospital

Department of Urology

300 Longwood Avenue

Hunnewell 390

Boston, MA 02115

Richard.Lee@childrens.harvard.edu

617-355-3348 (Phone)

617-730-0474 (fax) 
- Supporting Figure 1: Comparison of MALDI-MS of permethylated N-glycans of bovine fetuin by different Sample-Prep Strategies.

- Supporting Figure 2: Comparison of MALDI-MS of permethylated N-glycans of human serum IgG by different Sample-Prep Strategies.

- Supporting Figure 3: Comparison of MALDI-MS of permethylated N-glycans from two different murine kidneys.

- Supporting Figure 4: Comparison of MALDI-MS of permethylated N-glycans from two different murine bladders.

- Supporting Figure 5: MALDI-MS of permethylated $\mathrm{N}$-glycans from human urine specimen.

- Supporting Figure 6: Replicate LC-MS/MS total ion chromatographs (TIC) of fetuin tryptic peptides obtained using the SRS method.

- Supporting Figure 7: Proteomic and glycoproteomic comparison of technical or biologic replicates of various biologic samples processed by SRS.

- Supporting Figure 8: Comparison of MALDI-MS of permethylated N-glycans from DU145Ctrl and DU145KD.

- Supporting Table 1: The identified N-glycans from two different murine kidneys processed and analyzed using SRS and MALDI-MS.

- Supporting Table 2: The identified N-glycans from two different murine bladder tissue samples processed and analyzed using SRS and MALDI-MS.

- Supporting Table 3: Protein and tryptic peptide yield from the SRS platform for various biologic samples.

- Supporting Table 4: The tryptic peptides identified from SRS-bound bovine fetuin using LC-MS/MS.

- Supporting Table 5: Proteomic and glycoproteomics results for different biological samples processed using SRS.

- Supporting Table 6: N-glycans identified from DU145Ctrl and DU145KD cell lines processed and analyzed using SRS and MALDI-MS. 
(A) Solution-phase

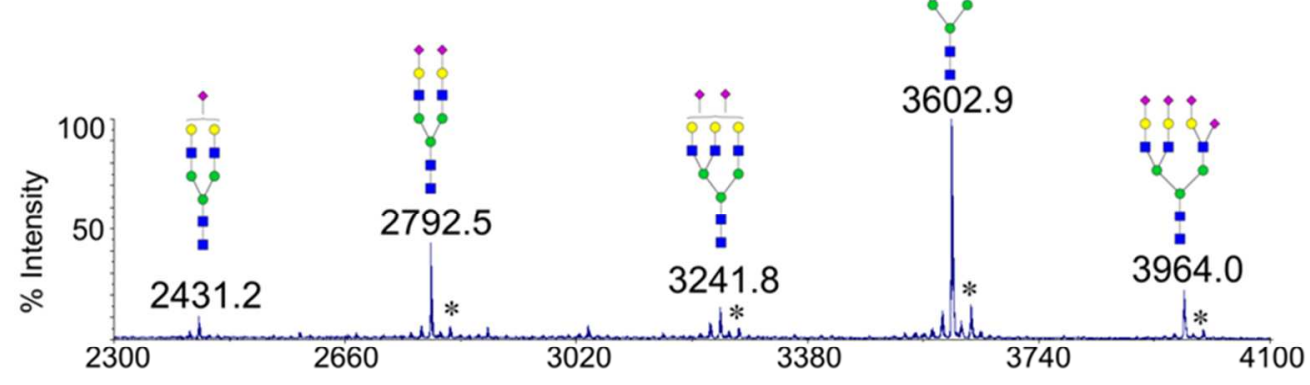

(B) SRS

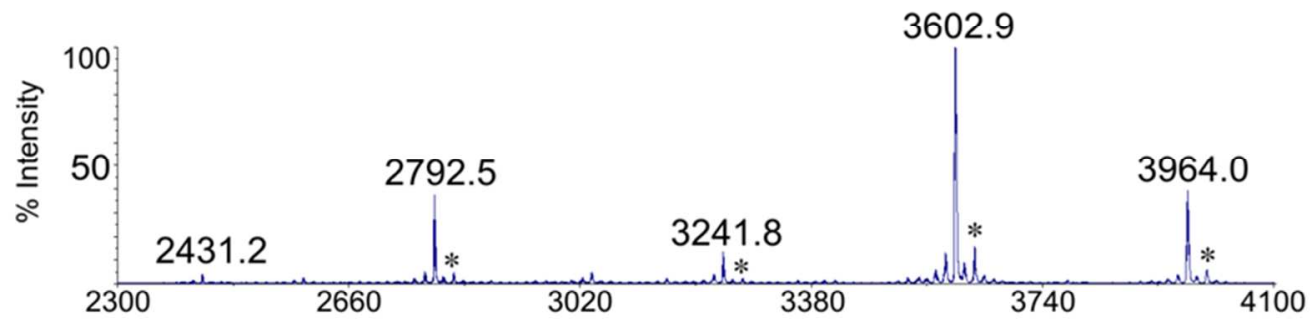

(C) SRS with SDS

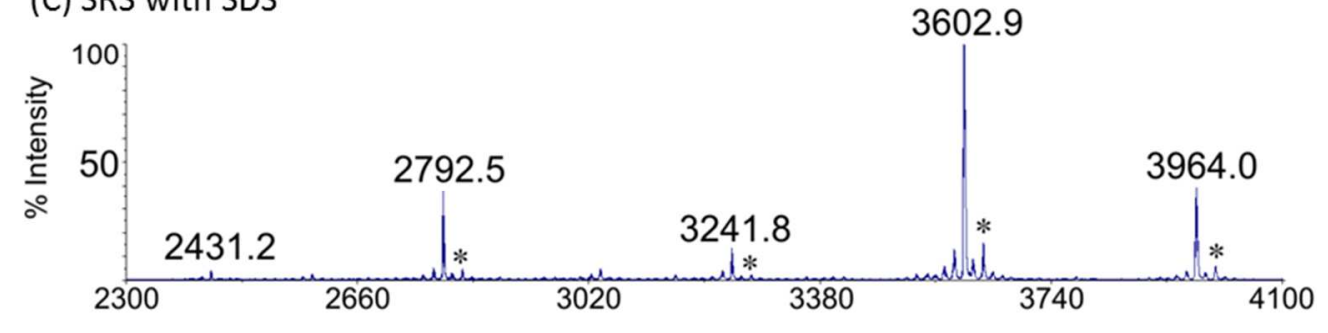

Supporting Figure 1|Comparison of MALDI-MS spectra of permethylated N-glycans of bovine fetuin by different Sample-Prep strategies: classic solution-phase strategy (A), SRS (B), and SRS with fetuin dissolved in $2 \%$ SDS /PBS (C). Asterisks peaks indicate that these glycans contain one or two N-glycolylneuraminic acid (Neu5Gc) residues, rather than abundant $\mathrm{N}$ acetylneuraminic acid (Neu5Ac). All peaks were single sodium adducts, and the monoisotopic peaks are annotated. All peaks were assigned a putative topology based on their $\mathrm{m} / \mathrm{z}$ values and N-glycosylation biosynthetic pathway. Further structural details, such as inter-residue linkage, anomericity, and branching pattern, were not determined. 


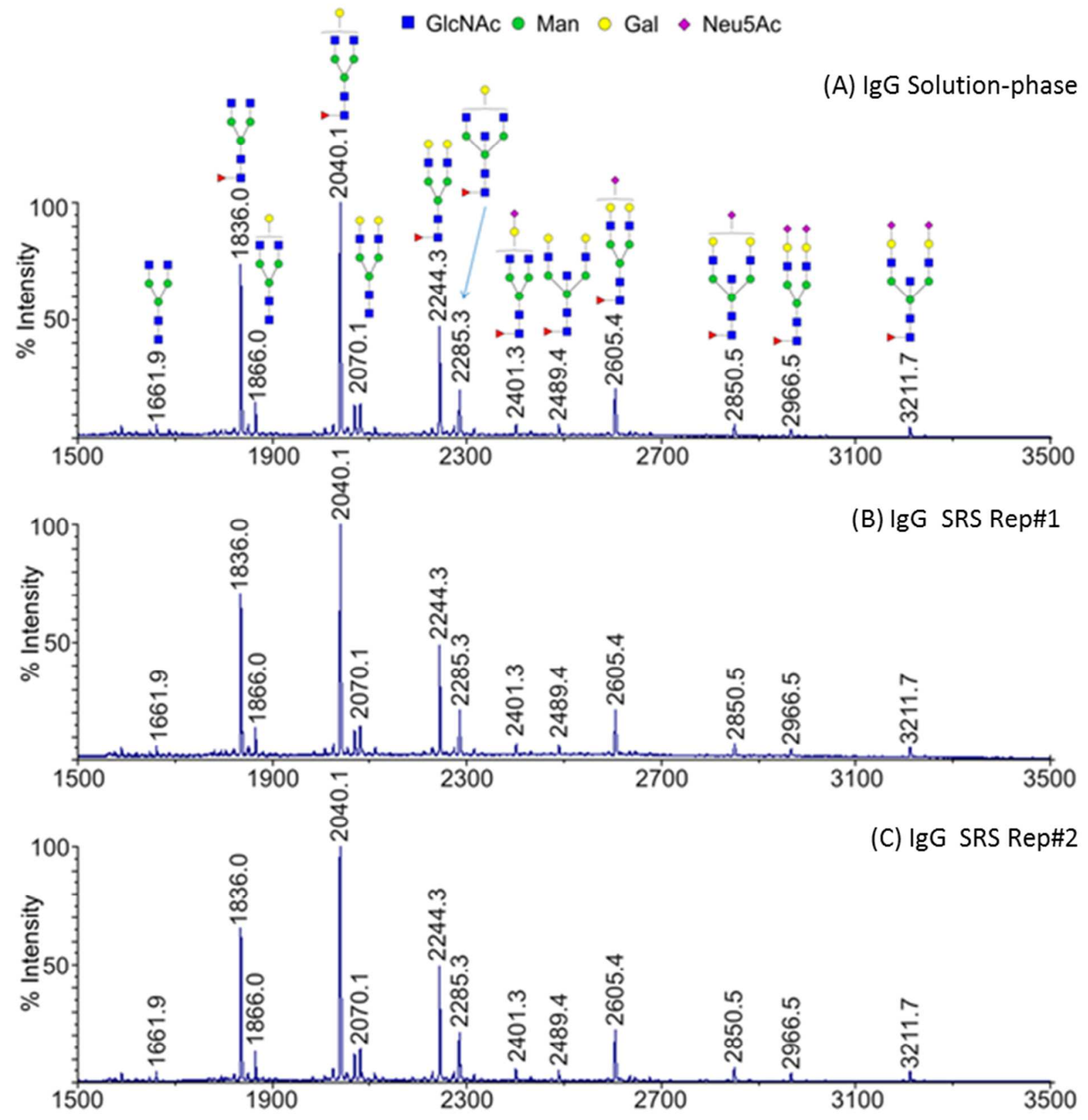

Supporting Figure 2| Comparison of MALDI-MS spectra of N-glycans released from human serum IgG by different Sample-Prep strategies: Solution-phase (A); SRS (Replicate \#1) (B); and SRS (Replicate \#2) (C). The three spectra were highly similar to each other, indicating the SRS strategy was comparable to the classical solution phase strategy. All peaks were single sodium adducts, and the monoisotopic peaks are annotated. All peaks were assigned a putative topology based on their $\mathrm{m} / \mathrm{z}$ values and $\mathrm{N}$-glycosylation biosynthetic pathway. Further structural details, such as inter-residue linkage, anomericity, and branching pattern, were not determined. 
(A) SRS_kidney\#1 Low-mass

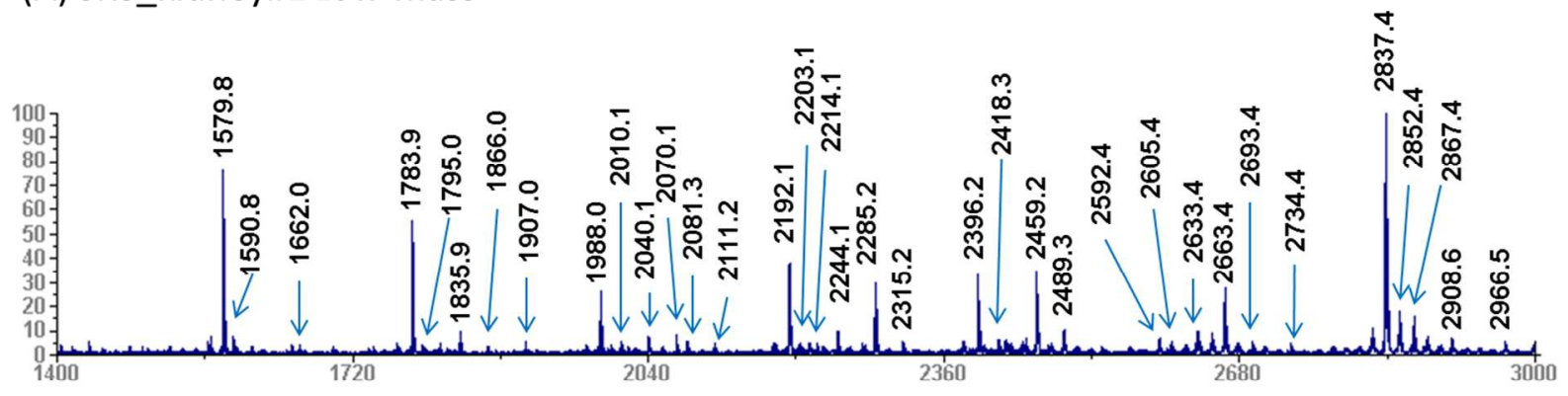

(B) SRS_kidney\#2 Low-mass
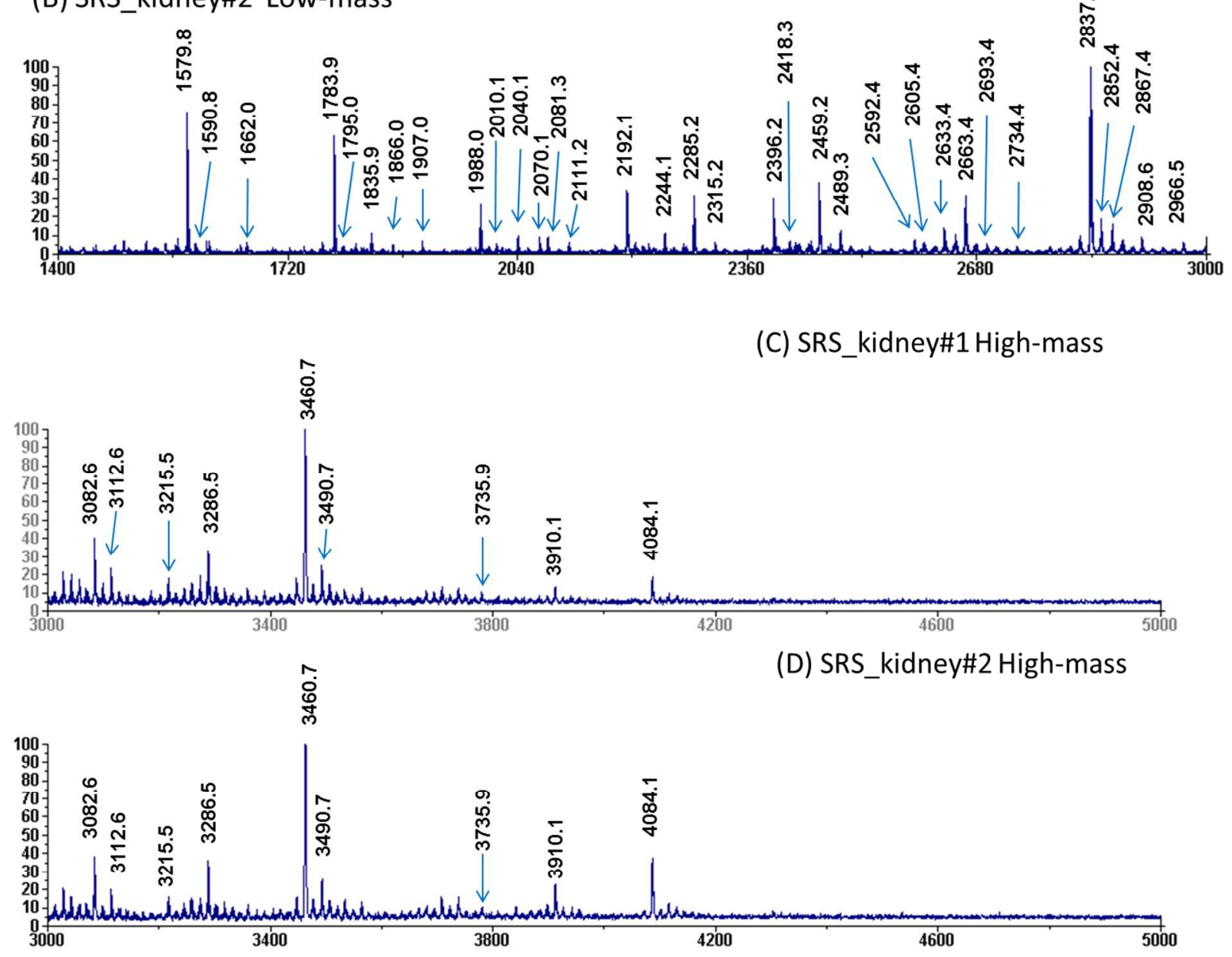

Supporting Figure 3: A comparison of the N-Glycome from two different murine kidneys (Kidney \#1 vs. Kidney \#2) processed and analyzed using SRS and MALDI-MS. All peaks were single sodium adducts, and the monoisotopic peaks were annotated. All peaks were assigned a putative topology based on their $\mathrm{m} / \mathrm{z}$ values and $\mathrm{N}$-glycosylation biosynthetic pathway as listed in Supporting Table 1. 


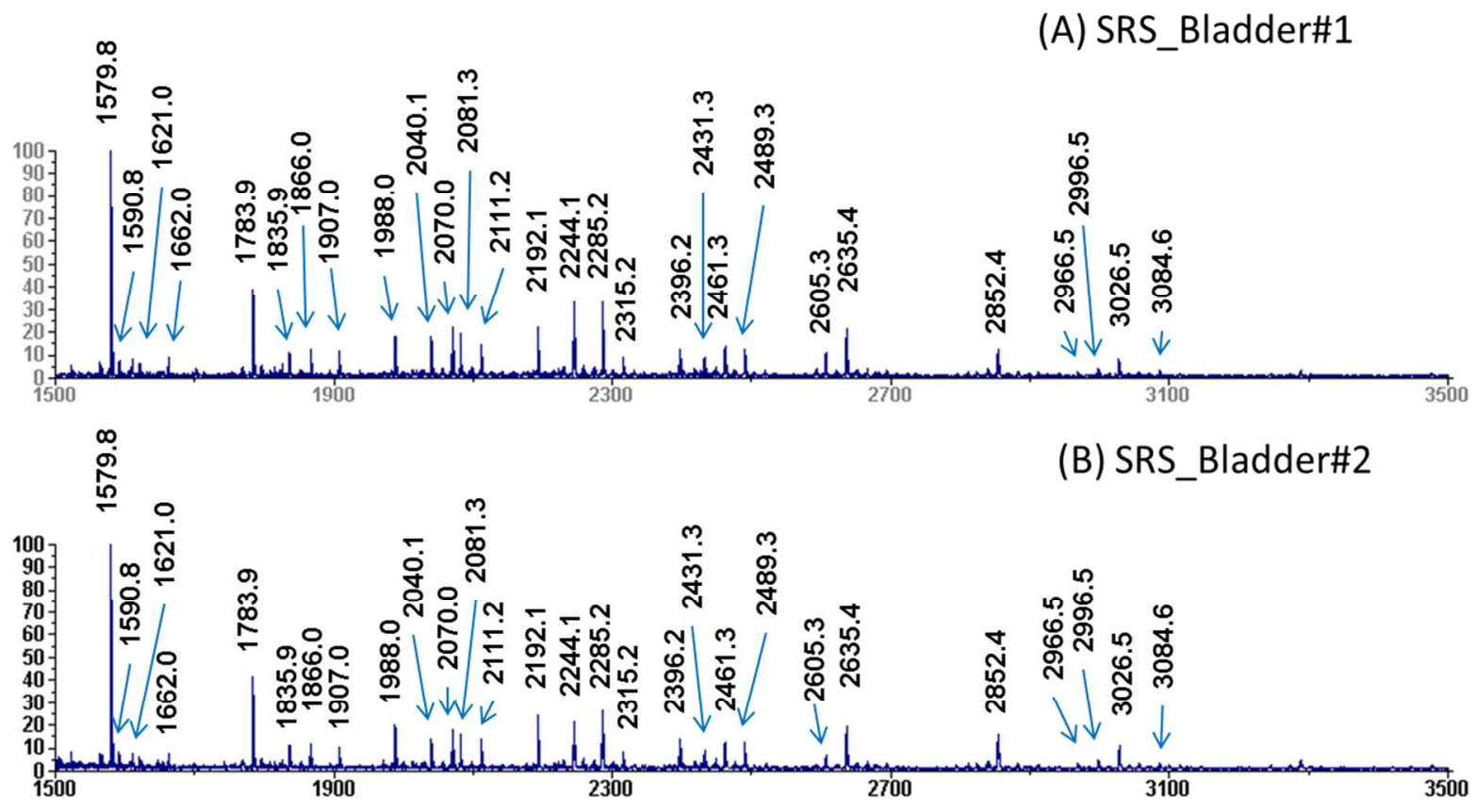

Supporting Figure 4: A comparison of the N-glycome from two different murine bladder tissue samples processed and analyzed using SRS and MALDI-MS (Bladder \#1 vs. Bladder \#2). All peaks were single sodium adducts, and the monoisotopic peaks were annotated. All peaks were assigned a putative topology based on their $\mathrm{m} / \mathrm{z}$ values and $\mathrm{N}$-glycosylation biosynthetic pathway as listed in Supporting Table 2. 


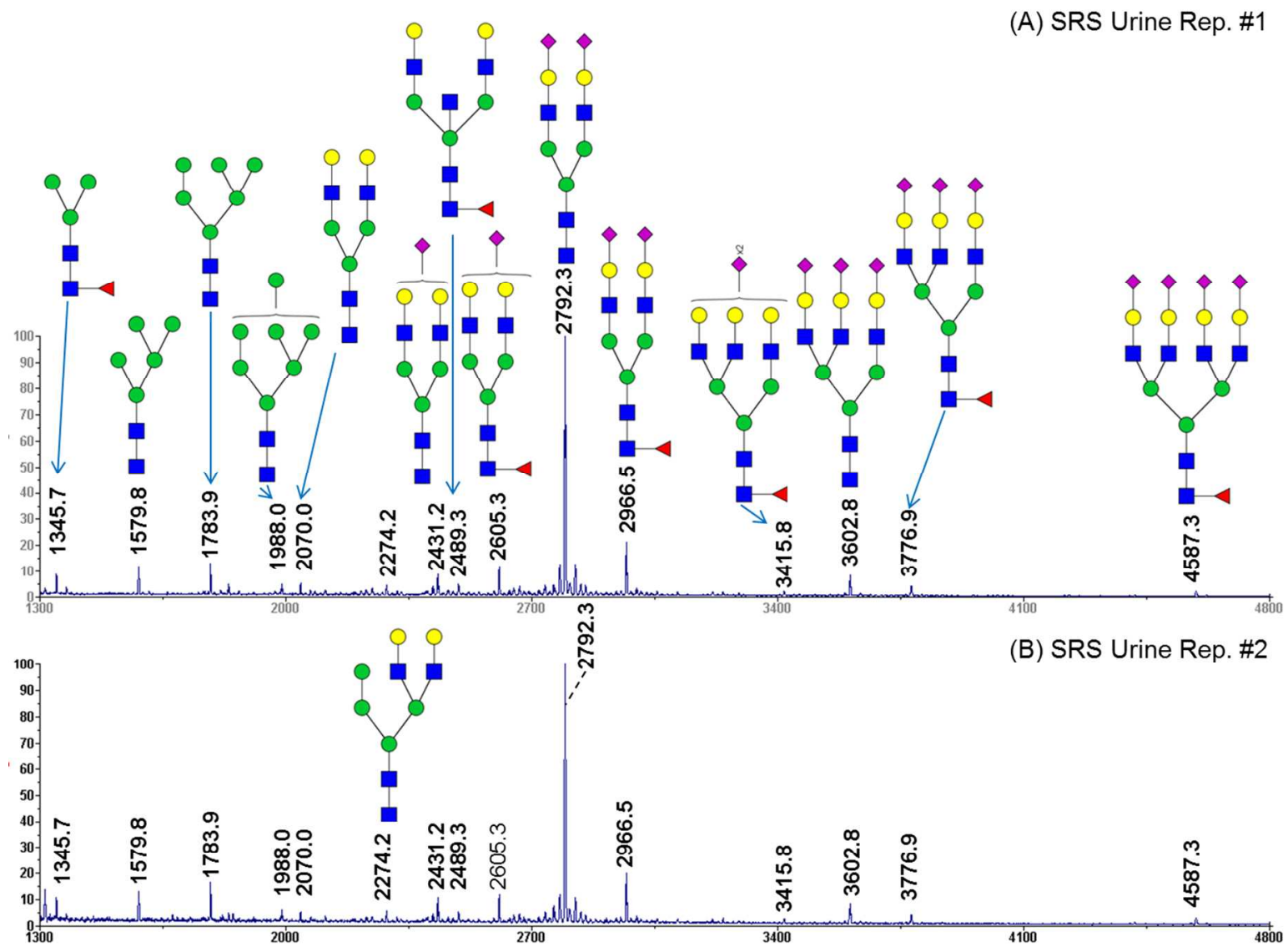

Supporting Figure 5: A comparison of a technical replicate (Rep\#1, Rep\#2) of the human urinary glycome obtained from a single urine sample processed and analyzed by SRS and MALDI-MS. Similar profiles were obtained for both replicates, indicating a high degree of reproducibility using the SRS approach. All peaks were single sodium adducts, and the monoisotopic peaks are annotated. The peaks were assigned a putative topology based on their $\mathrm{m} / \mathrm{z}$ values and N-glycosylation biosynthetic pathway. Further structural details, such as interresidue linkage, anomericity, and branching pattern, were not determined. [ $\mathrm{N}$-acetyl glucosamine; $\bigcirc$ mannose; $\bigcirc$ galactose; $\Delta$ fucose; $\diamond \mathrm{N}$-acetylneuraminic acid (Neu5Ac).] 


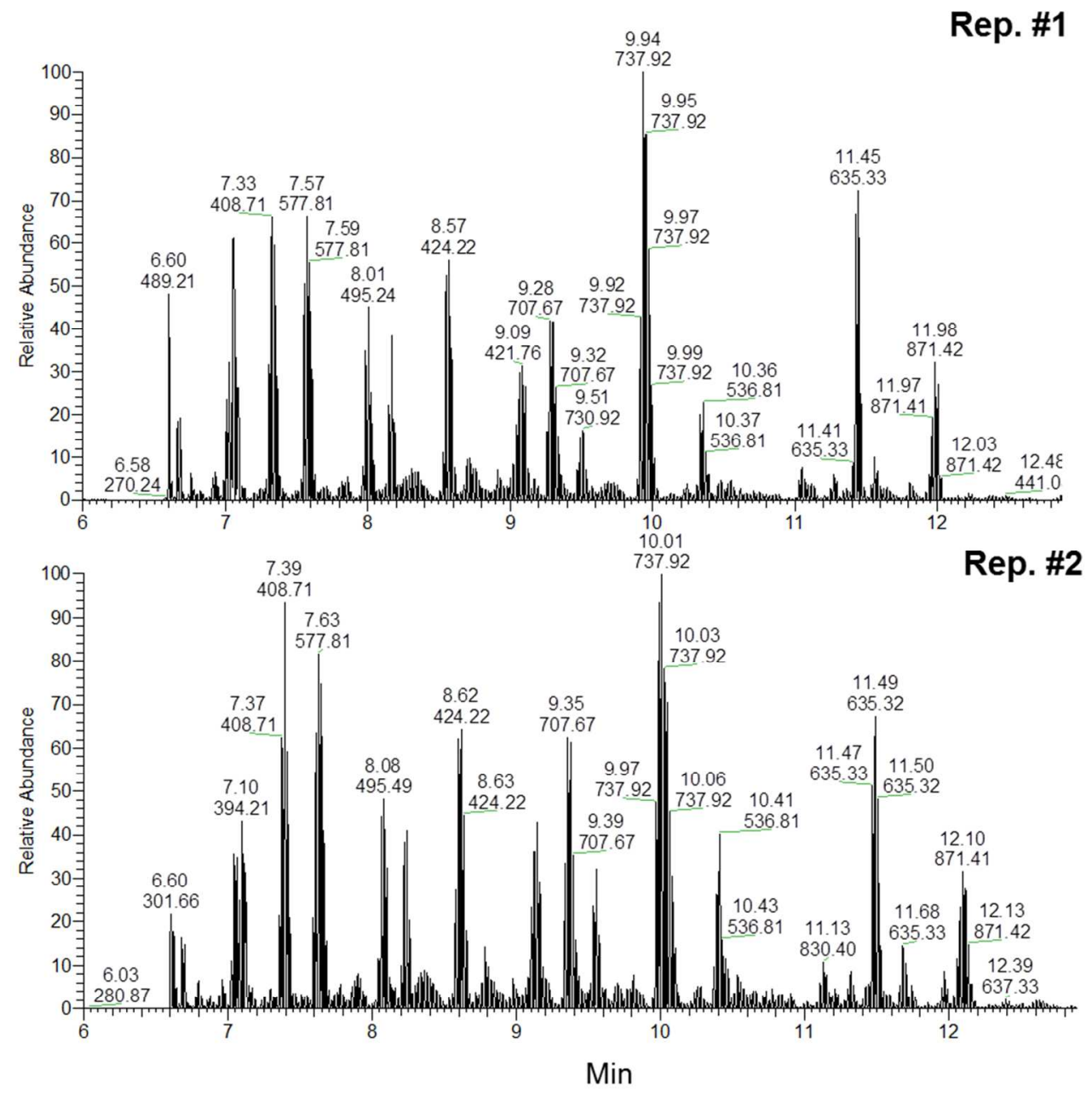

Supporting Figure 6: Replicate LC-MS/MS total ion chromatographs (TIC) of fetuin tryptic peptides obtained using the SRS strategy (Rep \#1, Rep \#2). The identified tryptic peptides are listed in Supporting Table 5. The TIC spectra were nearly identical between both replicates, suggesting that SRS is highly reproducible. 
A) DU145Ctrl

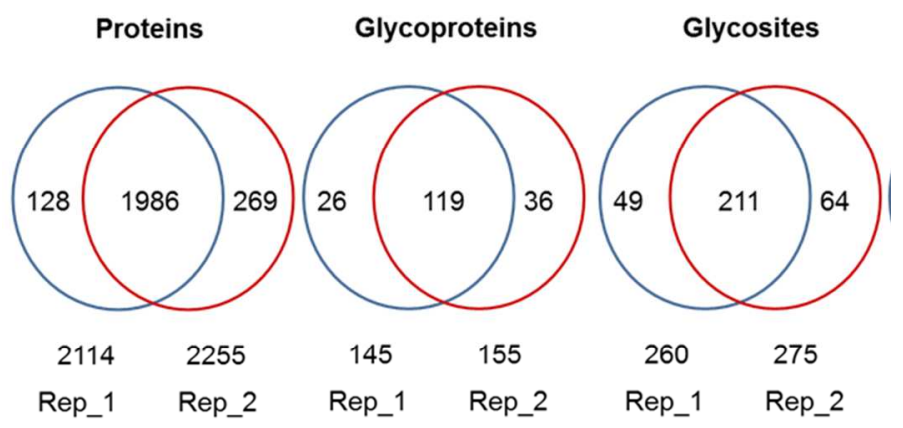

B) DU145KD

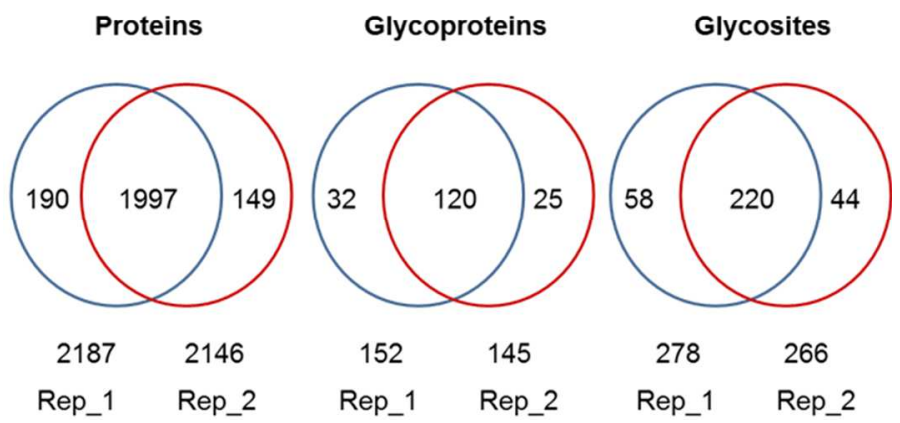

C) Mouse colon

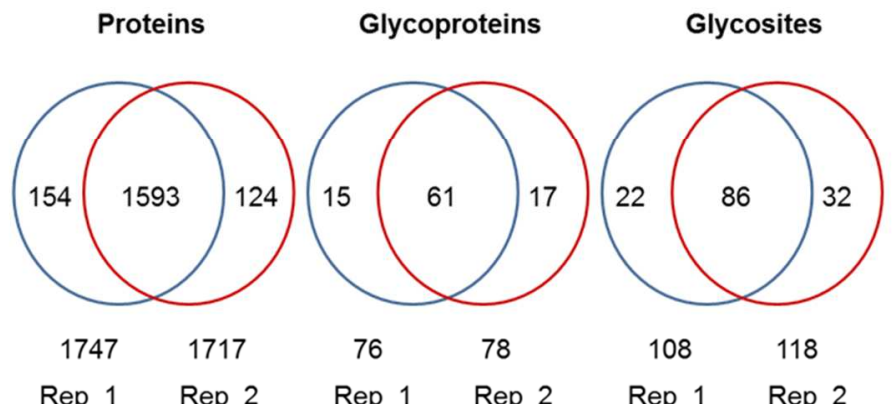

Rep_1 Rep_2 Rep_1 Rep_2 Rep_1 Rep_2

\section{D) Adult urine specimen}

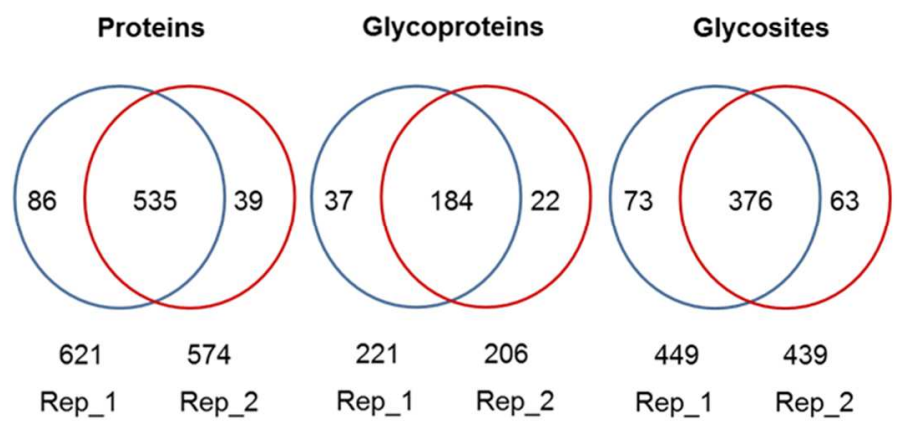

Supporting Figure 7: Proteomic and glycoproteomic comparison of technical or biologic replicates of various biologic samples processed by SRS. Venn-Diagrams represent the following: A) technical replicates of DU145Ctrl, membrane-enriched; B) technical replicates of 
DU145KD, membrane-enriched; C) Biological replicate of murine colon; and D) technical replicate of one adult urine specimen. 

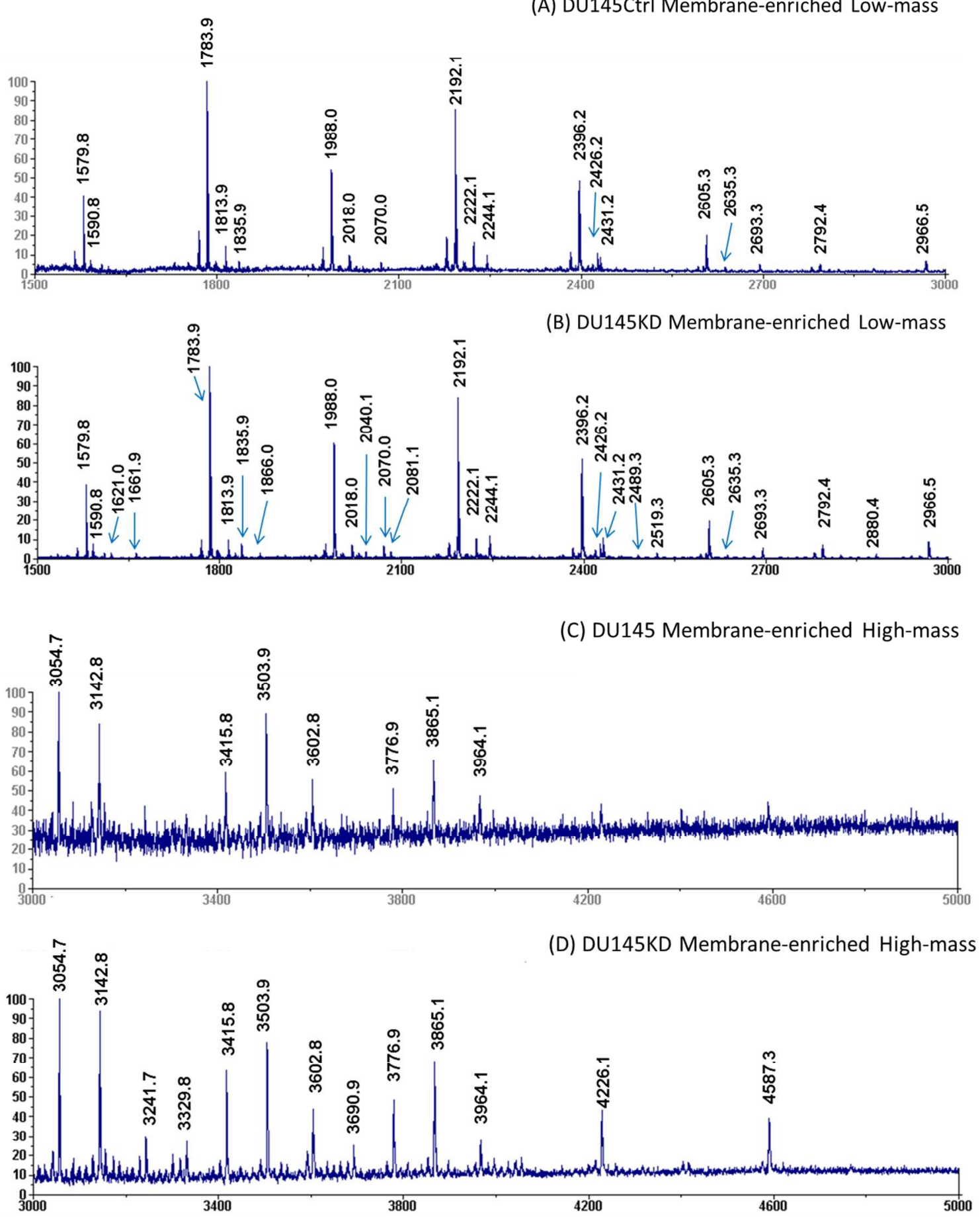

Supporting Figure 8: A comparison of the MALDI-MS spectra of permethylated N-glycans from DU145Ctrl and DU145KD cell lines obtained using SRS. All peaks were single sodium adducts, and the monoisotopic peaks were annotated. The identified peaks are listed in the Supporting Table 7. 
Supporting Table 1: The identified N-glycans from two different murine kidneys processed and analyzed using SRS and MALDI-MS. All peaks were assigned a putative topology based on their $\mathrm{m} / \mathrm{z}$ values and $\mathrm{N}$-glycosylation biosynthetic pathway. Further structural details, such as inter-residue linkage, anomericity, and branching pattern, were not determined. ( $\square \mathrm{N}$-acetyl glucosamine; $\bigcirc$ mannose; $\bigcirc$ galactose; $\Delta$ fucose; $\diamond \mathrm{N}$-acetylneuraminic acid (Neu5Ac); $\diamond N$ Glycolylneuraminic acid (Neu5Gc))

\begin{tabular}{|c|c|c|}
\hline $\begin{array}{l}\text { Glycan } \\
\#\end{array}$ & $\begin{array}{l}\text { Observed } \\
\mathrm{m} / \mathrm{z}\end{array}$ & Putative Topology \\
\hline 1 & 1579.8 & \\
\hline 2 & 1590.8 & \\
\hline 3 & 1662.0 & \\
\hline 4 & 1783.9 & \\
\hline 5 & 1795.0 & \\
\hline 6 & 1835.9 & $\Delta$ \\
\hline
\end{tabular}




\begin{tabular}{|c|c|c|}
\hline 7 & 1866.0 & $=-\infty=0$ \\
\hline 8 & 1907.0 & $=\left\{\begin{array}{l}0-1 \\
0-1\end{array}\right.$ \\
\hline 9 & 1988.0 & $\rightarrow$ \\
\hline 10 & 2010.1 & 1 \\
\hline 11 & 2040.1 & $1-\alpha$ \\
\hline 12 & 2070.0 & $=0$ \\
\hline 13 & 2081.3 & $=a_{0}^{0}$ \\
\hline
\end{tabular}




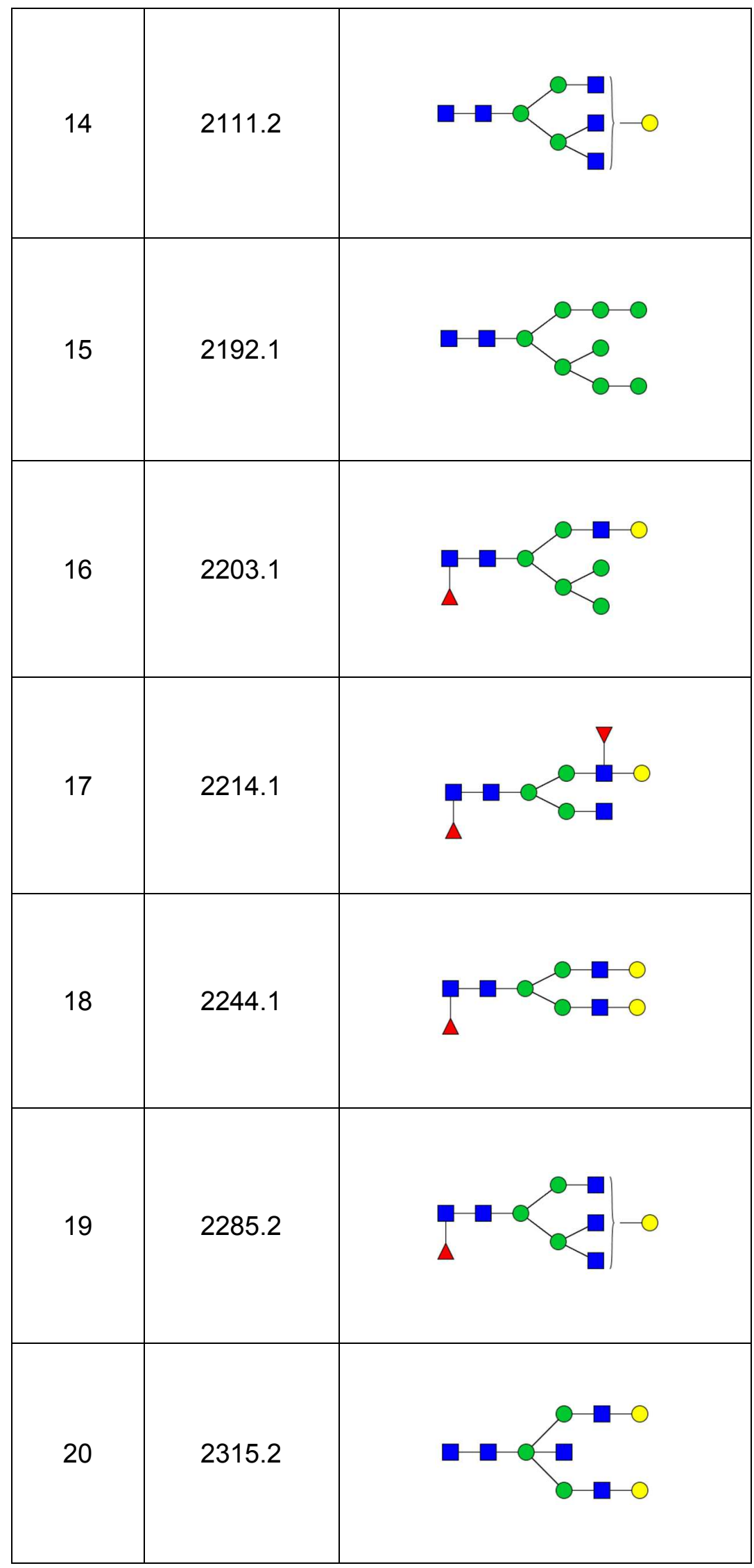




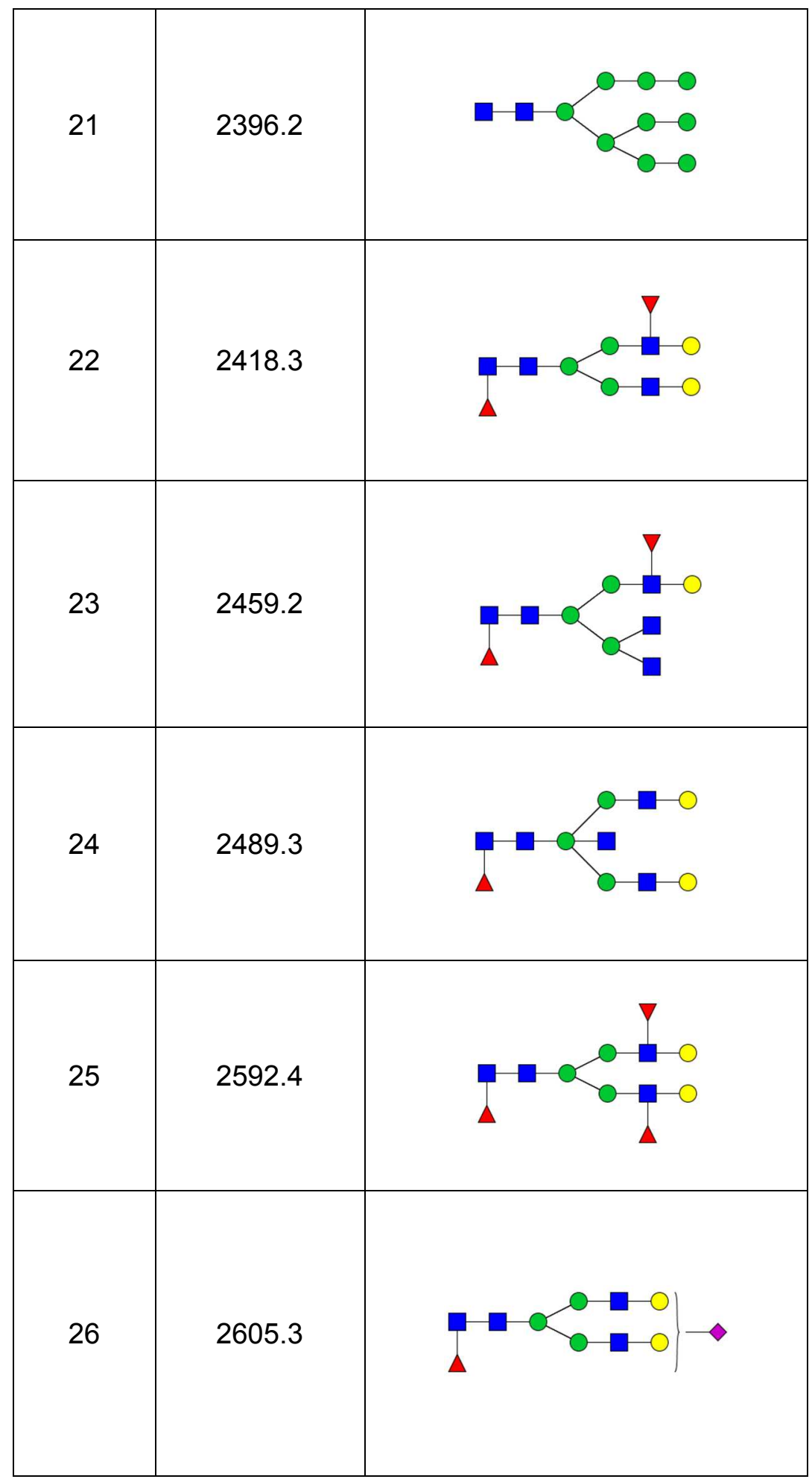




\begin{tabular}{|c|c|c|}
\hline 27 & 2633.4 & $=\sum_{1}^{1}$ \\
\hline 28 & 2663.4 & $=\sum_{-\infty}^{1}$ \\
\hline 29 & 2693.4 & $=\alpha_{0-0}^{0-0}$ \\
\hline 30 & 2734.4 & 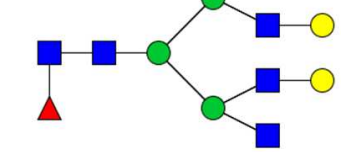 \\
\hline 31 & 2837.4 & $=\sum_{-1}^{0-1}$ \\
\hline 32 & 2852.4 & $=\alpha_{0-\infty}^{0}=$ \\
\hline
\end{tabular}




\begin{tabular}{|c|c|c|}
\hline 33 & 2867.4 & $=\alpha_{0-0}^{0-0}$ \\
\hline 34 & 2908.6 & 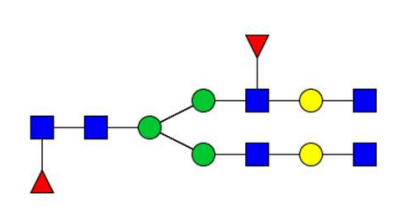 \\
\hline 35 & 2966.5 & 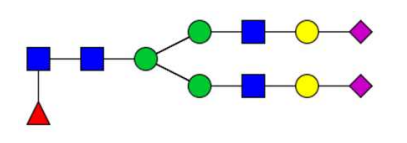 \\
\hline 36 & 3082.6 & 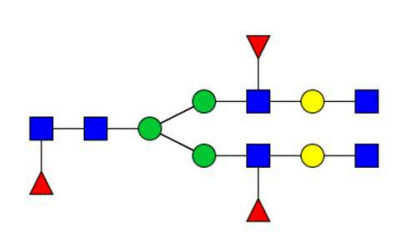 \\
\hline 37 & 3112.6 & $=\sum_{-0}^{1}$ \\
\hline 38 & 3215.5 & $\lim _{0}+\sum_{-\infty}$ \\
\hline
\end{tabular}




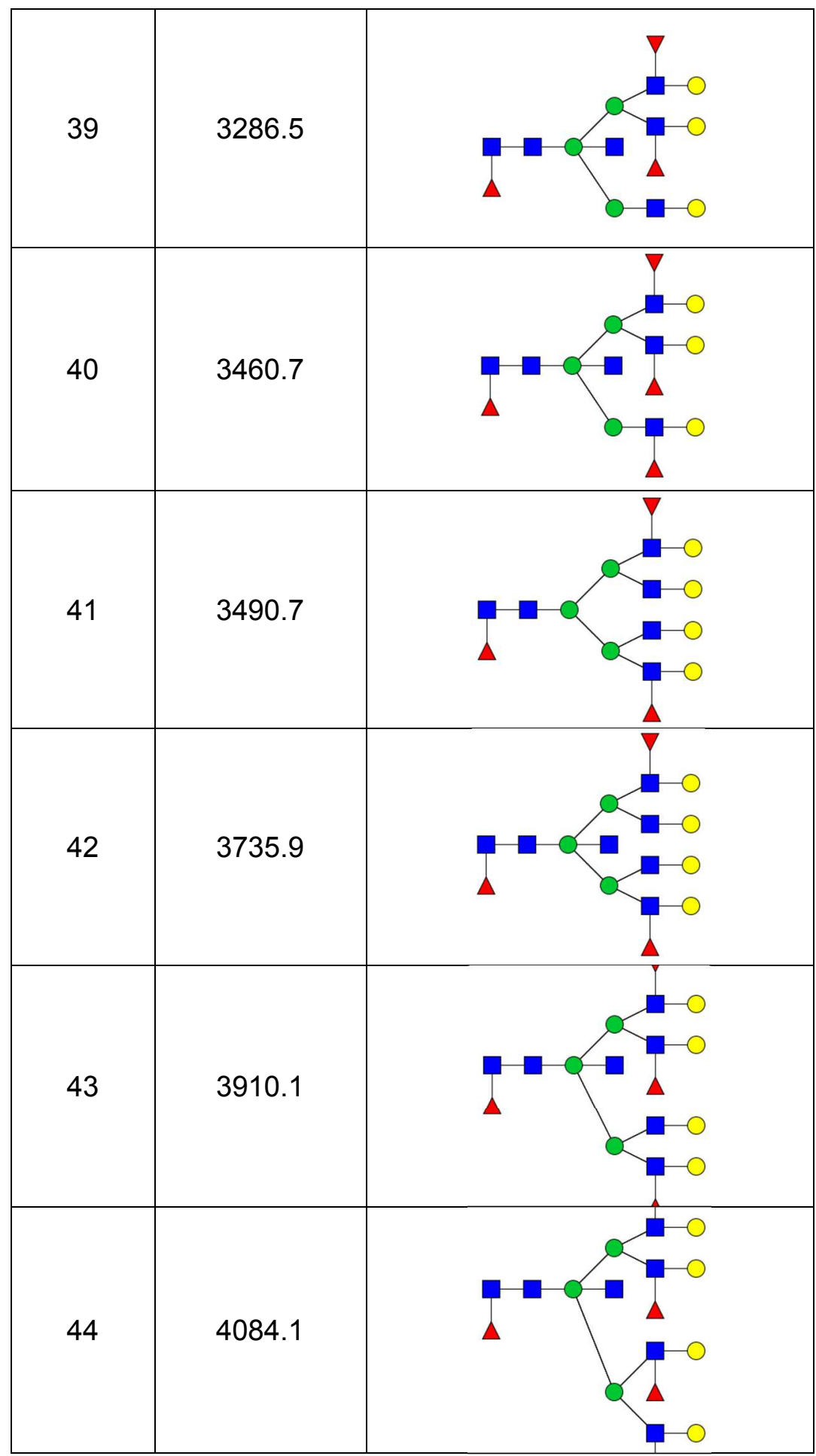


Supporting Table 2: The identified N-glycans from two different murine bladder tissue samples processed and analyzed using SRS and MALDI-MS. All peaks were assigned a putative topology based on their $\mathrm{m} / \mathrm{z}$ values and $\mathrm{N}$-glycosylation biosynthetic pathway. Further structural details, such as inter-residue linkage, anomericity, and branching pattern, were not determined. ( $\square$-acetyl glucosamine; $\bigcirc$ mannose; $\bigcirc$ galactose; $\Delta$ fucose; $\diamond \mathrm{N}$-acetylneuraminic acid (Neu5Ac); $\diamond \mathrm{N}$-Glycolylneuraminic acid (Neu5Gc))

\begin{tabular}{|c|c|c|}
\hline Glycan\# & $\begin{array}{l}\text { Observed } \\
\mathrm{m} / \mathrm{z}\end{array}$ & Putative Topology \\
\hline 1 & 1579.8 & \\
\hline 2 & 1590.8 & \\
\hline 3 & 1662.0 & \\
\hline 4 & 1783.9 & \\
\hline 5 & 1835.9 & \\
\hline 6 & 1866.0 & $\square-\square$ \\
\hline
\end{tabular}




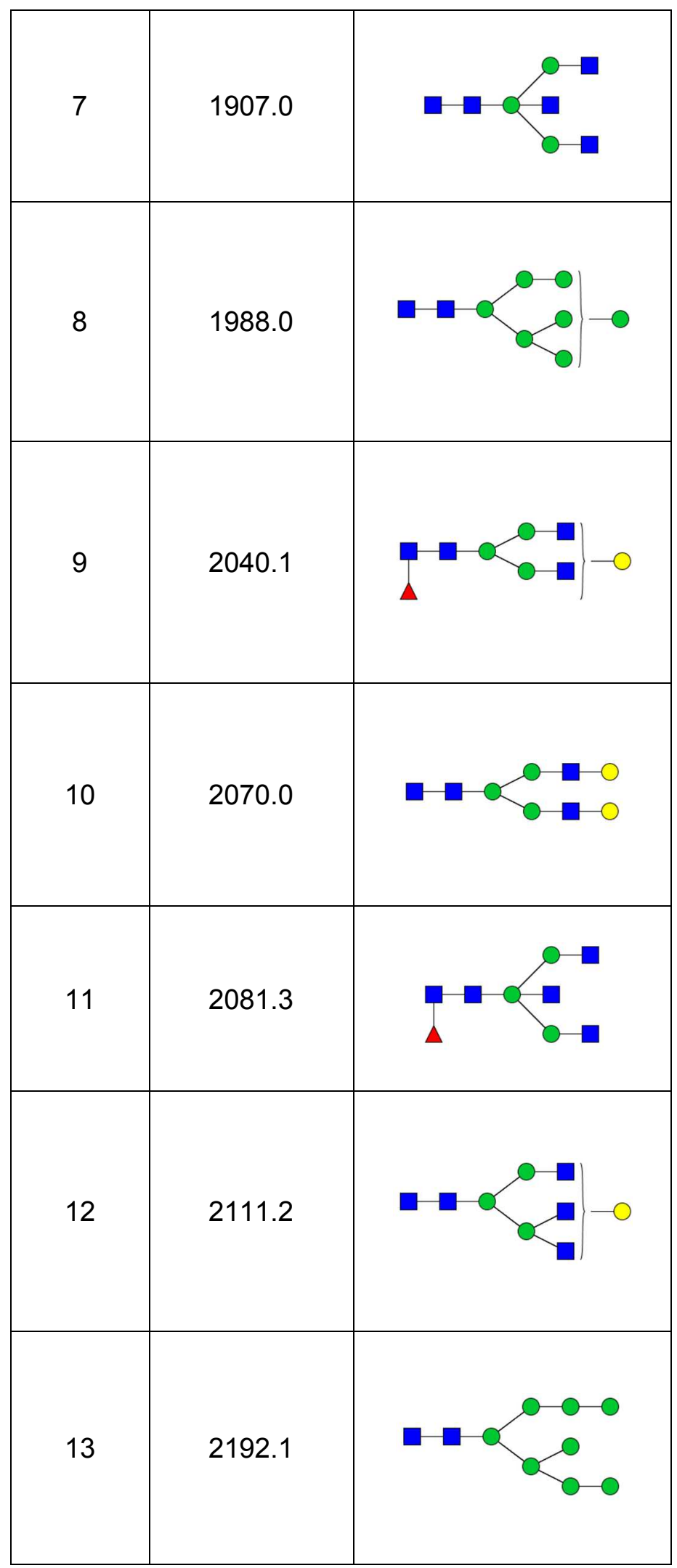




\begin{tabular}{|c|c|c|}
\hline 14 & 2244.1 & $x-\infty=0$ \\
\hline 15 & 2285.2 & $=0$ \\
\hline 16 & 2315.2 & - \\
\hline 17 & 2396.2 & \\
\hline 18 & 2431.3 & $\left.\begin{array}{ccc}0 & -1 & 0 \\
0 & -0 & 0\end{array}\right\} \rightarrow$ \\
\hline 19 & 2461.3 & 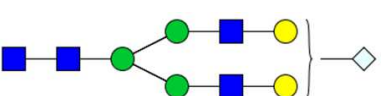 \\
\hline
\end{tabular}




\begin{tabular}{|c|c|c|}
\hline 20 & 2489.3 & $=\left\{\begin{array}{l}0 \\
0-0\end{array}\right.$ \\
\hline 21 & 2605.3 & $\left|\begin{array}{lllll}- & 0 & 0 & - & -0 \\
1 & 0 & - & -0\end{array}\right| \rightarrow$ \\
\hline 22 & 2635.4 & $\left|\begin{array}{llll}- & 0 & - & -0 \\
0 & 0 & - & 0\end{array}\right| \rightarrow$ \\
\hline 23 & 2852.4 & 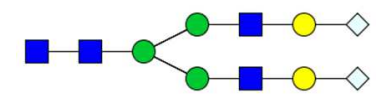 \\
\hline 24 & 2966.5 & $=\alpha_{0}^{0}=0$ \\
\hline 25 & 2996.5 & $\rightarrow$ \\
\hline
\end{tabular}




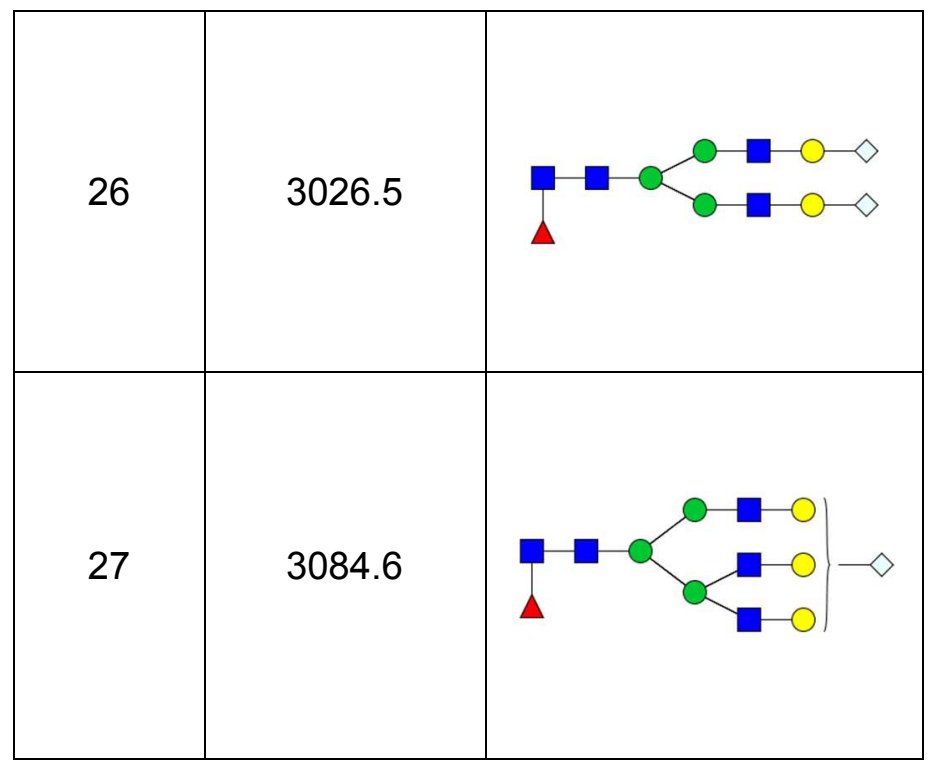


Supporting Table 3: Protein and tryptic peptide yield from the SRS platform for various biologic samples. Protein concentration was measured in triplicate using the BCA assay. The concentrations of peptides were estimated based on an in-house peptide concentration standard curve (A205 - Nanodrop spectrophotometer, Thermo Fisher Scientific).

\begin{tabular}{|l|c|c|c|c|c|}
\hline \multicolumn{1}{|c|}{$\begin{array}{c}\text { Sample } \\
\text { Types } \\
\text { (ug) }\end{array}$} & Starting & Bound & $\begin{array}{c}\text { Stripped } \\
\text { proteins }\end{array}$ & $\begin{array}{c}\text { Extracted } \\
\text { peptides }\end{array}$ & $\begin{array}{c}\text { Recovery } \\
\text { yield (\%) }\end{array}$ \\
\hline Fetuin (A) & 300 & 266 & 258 & N/A & 97 \\
\hline Fetuin (B) & 300 & 289 & 251 & N/A & 87 \\
\hline Fetuin (C) & 300 & 265 & N/A & 248 & 94 \\
\hline Fetuin (D) & 300 & 272 & N/A & 251 & 92 \\
\hline Serum IgG (A) & 300 & 282 & 264 & N/A & 94 \\
\hline Serum IgG (B) & 300 & 284 & 272 & N/A & 97 \\
\hline $\begin{array}{l}\text { Membrane- } \\
\text { enriched } \\
\text { DU145Ctrl (A) }\end{array}$ & 400 & 365 & N/A & 321 & 88 \\
\hline $\begin{array}{l}\text { Membrane- } \\
\text { enriched } \\
\text { DU145Ctrl (B) }\end{array}$ & 400 & 363 & N/A & 315 & 87 \\
\hline $\begin{array}{l}\text { Membrane- } \\
\text { enriched } \\
\text { DU145KD (A) }\end{array}$ & 400 & 352 & N/A & 310 & 88 \\
\hline $\begin{array}{l}\text { Membrane- } \\
\text { enriched } \\
\text { DU145KD (B) }\end{array}$ & 400 & 359 & N/A & 309 & 86 \\
\hline
\end{tabular}


Supporting Table 4: The tryptic peptides identified from SRS-bound bovine fetuin using LCMS/MS. The charge states of observed peptides are annotated in parentheses. Three de-Nglycosylated motifs were located within three tryptic peptides of 72-103 (NS), 145-159 (NDS) and 160-187 (NGS). The majority of known tryptic peptides were detected, with the exception of several that were too small or too large, and not identified because of MS limitations.

\begin{tabular}{|c|c|c|c|c|}
\hline AA Positions & Peptide sequence & Calc. $[\mathrm{M}+\mathrm{H}]^{+}$ & Rep.\#1 & Rep.\#2 \\
\hline $19-28$ & IPLDPVAGYK & 1072.6037 & $536.8057(2)$ & $536.8055(2)$ \\
\hline $29-50$ & EPACDDPDTEQAALAAVDYINK & 2406.0557 & $1203.5417(2)$ & $1203.5410(2)$ \\
\hline $51-54$ & HLPR & 522.3152 & $261.6598(2)$ & $261.6598(2)$ \\
\hline $55-57$ & GYK & 367.1982 & $\mathrm{~N} / \mathrm{A}$ & $\mathrm{N} / \mathrm{A}$ \\
\hline $58-67$ & HTLNQIDSVK & 1154.617 & $557.8101(2)$ & $557.8100(2)$ \\
\hline $68-71$ & VWPR & 557.32 & $\mathrm{~N} / \mathrm{A}$ & $\mathrm{N} / \mathrm{A}$ \\
\hline $72-103$ & $\begin{array}{l}\text { RPTGEVYDIEIDTLETTCHVLDPT } \\
\text { PLANCSVR }\end{array}$ & 3672.7097 & $1224.9082(3)$ & $1224.9082(3)$ \\
\hline $104-120$ & QQTQHAVEGDCDIHVLK & 1977.9238 & $659.9838(3)$ & $659.9812(3)$ \\
\hline $121-131$ & QDGQFSVLFTK & 1269.6479 & $635.3251(2)$ & $635.3242(2)$ \\
\hline $132-143$ & CDSSPDSAEDVR & 1337.5065 & $669.2568(2)$ & $669.2565(2)$ \\
\hline $145-159$ & LCPDCPLLAPL $\underline{N D S R}$ & 1741.7824 & $871.4134(2)$ & $871.4102(2)$ \\
\hline $160-187$ & $\begin{array}{l}\text { VVHAVEVALATFNAESNGSLQLV } \\
\text { EISR }\end{array}$ & 3017.5584 & $1509.2840(2)$ & $1509.2826(2)$ \\
\hline $188-211$ & AQFVPLPVSVSVEFAVAATDCIAK & 2519.3005 & $\mathrm{~N} / \mathrm{A}$ & $\mathrm{N} / \mathrm{A}$ \\
\hline $212-218$ & EVVDPTK & 787.4202 & $394.2115(2)$ & $394.2140(2)$ \\
\hline $219-225$ & CNLLAEK & 847.4132 & $424.2198(2)$ & $424.2163(2)$ \\
\hline $226-231$ & QYGFCK & 802.3343 & $\mathrm{~N} / \mathrm{A}$ & $\mathrm{N} / \mathrm{A}$ \\
\hline $232-237$ & GSVIQK & 631.3779 & $316.1905(2)$ & $316.1943(2)$ \\
\hline $238-245$ & ALGGEDVR & 816.4216 & $408.7124(2)$ & $408.7145(2)$ \\
\hline $246-306$ & $\begin{array}{l}\text { VTCTLFQTQPVIPQPQPDGA } \\
\text { EAEAPSAVPDAAGPTPSAAG } \\
\text { PPVASVVVGPSVVAVPLPLHR }\end{array}$ & 6015.1116 & $\mathrm{~N} / \mathrm{A}$ & $\mathrm{N} / \mathrm{A}$ \\
\hline $307-312$ & AHYDLR & 774.3899 & $387.6964(2)$ & $387.6935(2)$ \\
\hline 313-333 & HTFSGVASVESSSGEAFHVGK & 2120.0049 & $707.3426(3)$ & $707.3418(3)$ \\
\hline $334-348$ & TPIVGQPSIPGGPVR & 1474.8382 & $737.9231(2)$ & $737.9216(2)$ \\
\hline $349-353$ & LCPGR & 602.287 & $\mathrm{~N} / \mathrm{A}$ & $\mathrm{N} / \mathrm{A}$ \\
\hline $354-355$ & IR & 288.2036 & $\mathrm{~N} / \mathrm{A}$ & $\mathrm{N} / \mathrm{A}$ \\
\hline 356---359 & YFKI & 570.3292 & $\mathrm{~N} / \mathrm{A}$ & $\mathrm{N} / \mathrm{A}$ \\
\hline
\end{tabular}


Supporting Table 5: Proteomic and glycoproteomics results for different biological samples processed using SRS. Experimental and bioinformatics procedures are described in Experimental section.

\begin{tabular}{|c|c|c|c|c|c|}
\hline Samples & Proteins & Peptides & Deglycopeptides & Glycosites & Glycoproteins \\
\hline \begin{tabular}{|l|} 
DU145Ctrl \\
Membrane- \\
enriched Rep\#1 \\
\end{tabular} & 2114 & 19699 & 251 & 260 & 145 \\
\hline \begin{tabular}{|l|} 
DU145Ctrl \\
Membrane- \\
enriched Rep\#2 \\
\end{tabular} & 2255 & 21007 & 270 & 275 & 155 \\
\hline $\begin{array}{l}\text { DU145KD } \\
\text { Membrane- } \\
\text { enriched Rep\#1 }\end{array}$ & 2187 & 19475 & 263 & 278 & 152 \\
\hline $\begin{array}{l}\text { DU145KD } \\
\text { Membrane- } \\
\text { enriched Rep\#2 }\end{array}$ & 2146 & 19010 & 251 & 264 & 145 \\
\hline $\begin{array}{l}\text { DU145Ctrl } \\
\text { Membrane- } \\
\text { enriched } \\
\text { Combined \#1\&\#2 }\end{array}$ & 2386 & 23793 & 319 & 322 & 179 \\
\hline $\begin{array}{l}\text { DU145KD } \\
\text { Membrane- } \\
\text { enriched } \\
\text { Combined \#1\&\#2 }\end{array}$ & 2340 & 21799 & 308 & 320 & 175 \\
\hline \begin{tabular}{|l|} 
Mouse Colon \\
Membrane- \\
enriched Rep\#1
\end{tabular} & 1747 & 14427 & 106 & 108 & 76 \\
\hline \begin{tabular}{|l} 
Mouse Colon \\
Membrane- \\
enriched Rep b\#2
\end{tabular} & 1717 & 14152 & 115 & 118 & 78 \\
\hline $\begin{array}{l}\text { Human Urine } \\
\text { Rep\#1 }\end{array}$ & 621 & 5396 & 455 & 449 & 221 \\
\hline $\begin{array}{l}\text { Human Urine } \\
\text { Rep\#2 }\end{array}$ & 574 & 5218 & 447 & 439 & 206 \\
\hline
\end{tabular}


Supporting Table 6: N-glycans identified from DU145Ctrl and DU145KD cell lines processed and analyzed using SRS and MALDI-MS. All peaks were assigned a putative topology based on their $\mathrm{m} / \mathrm{z}$ values and $\mathrm{N}$-glycosylation biosynthetic pathway. Further structural details, such as inter-residue linkage, anomericity, and branching pattern, were not determined. [ $\square \mathrm{N}$-acetyl glucosamine; $\bigcirc$ mannose; $\bigcirc$ galactose; $\Delta$ fucose; $\diamond \mathrm{N}$-acetylneuraminic acid (Neu5Ac).]

\begin{tabular}{|c|c|c|}
\hline $\begin{array}{l}\text { Glycan } \\
\#\end{array}$ & $\begin{array}{l}\text { Observed } \\
\mathrm{m} / \mathrm{z}\end{array}$ & Putative Glycan \\
\hline 1 & 1579.8 & \\
\hline 2 & 1590.8 & \\
\hline 3 & 1661.9 & \\
\hline 4 & 1621.0 & \\
\hline 5 & 1783.9 & \\
\hline 6 & 1835.9 & \\
\hline
\end{tabular}




\begin{tabular}{|c|c|c|}
\hline 7 & 1866.0 & $=-\infty=0$ \\
\hline 8 & 1988.0 & م| \\
\hline 9 & 2040.1 & -0 \\
\hline 10 & 2070.0 & $a-c$ \\
\hline 11 & 2081.3 & $\int_{0}^{0}$ \\
\hline 12 & 2192.1 & \\
\hline 13 & 2244.1 & $1=-\infty 0$ \\
\hline
\end{tabular}




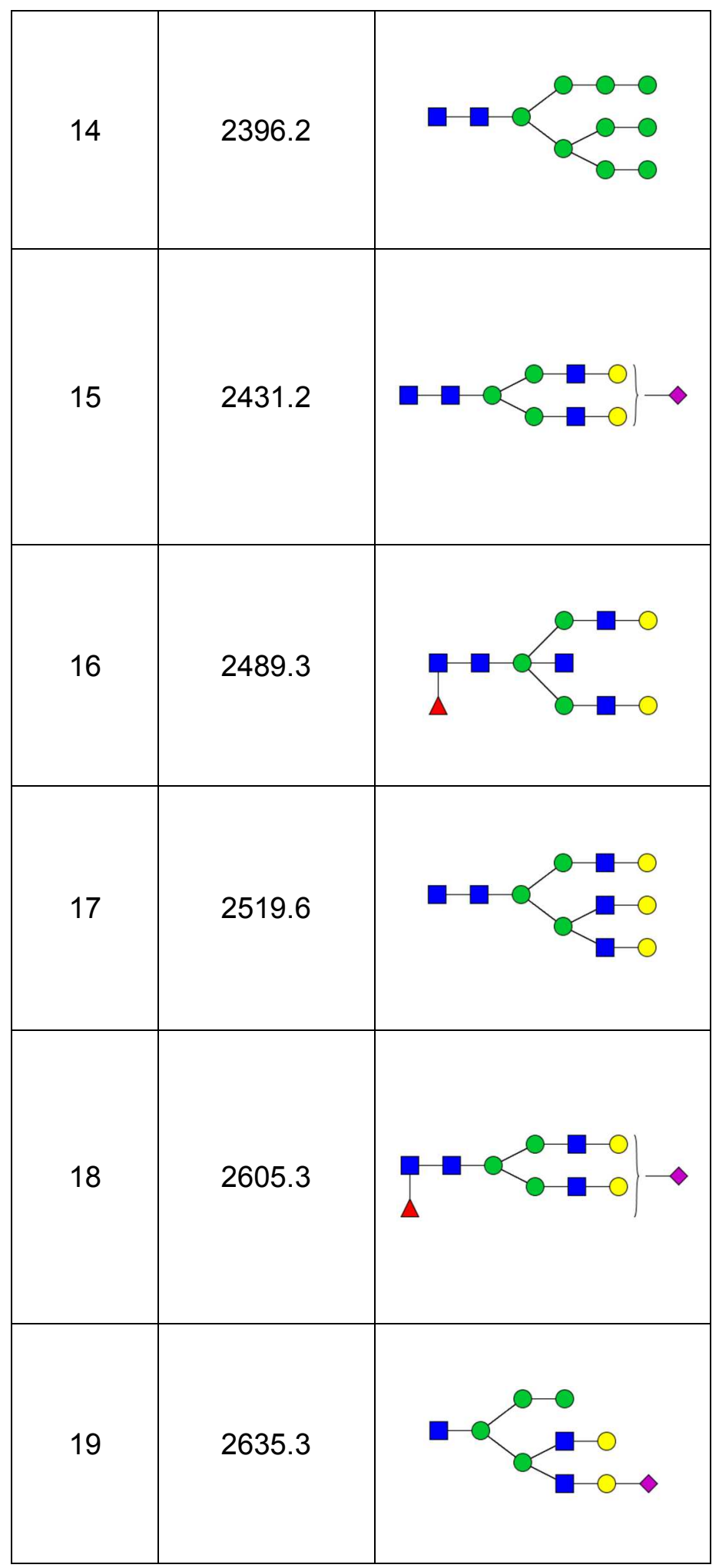




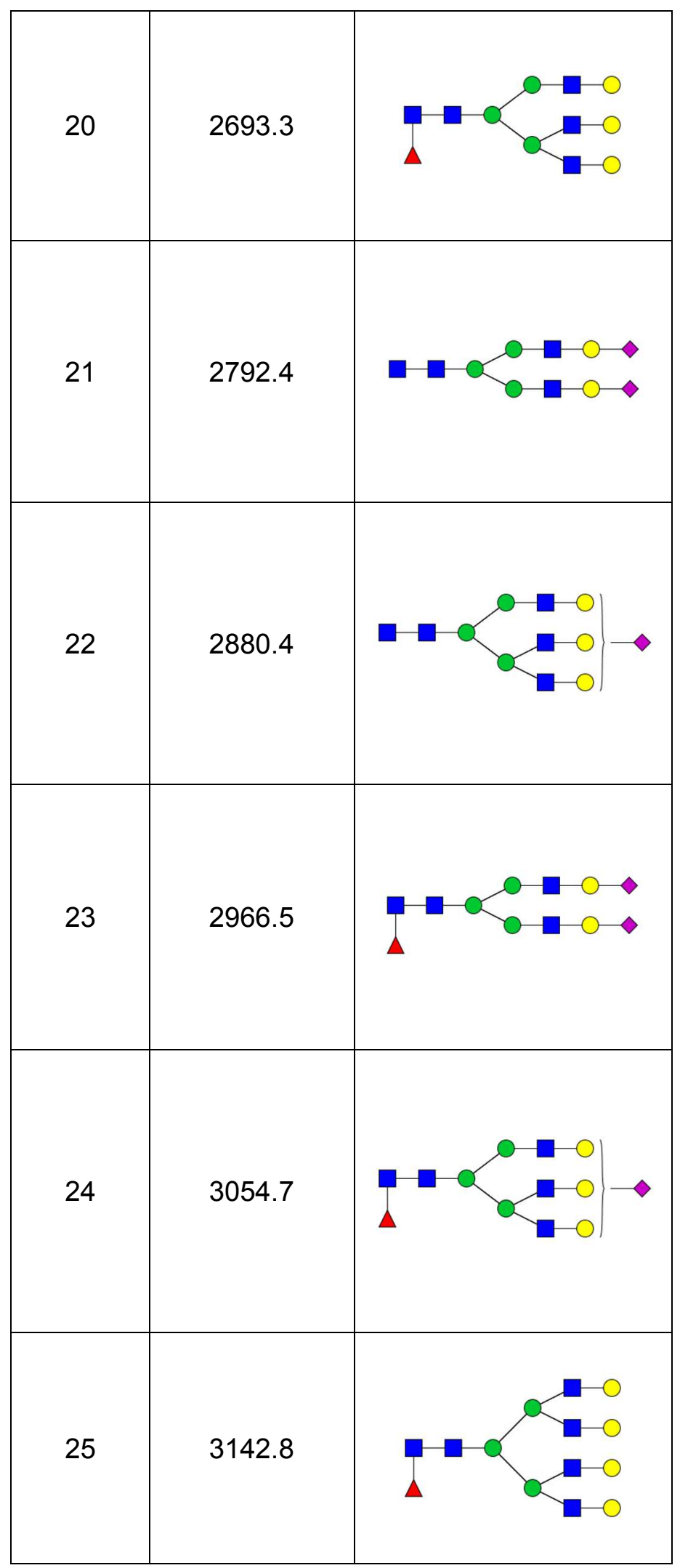




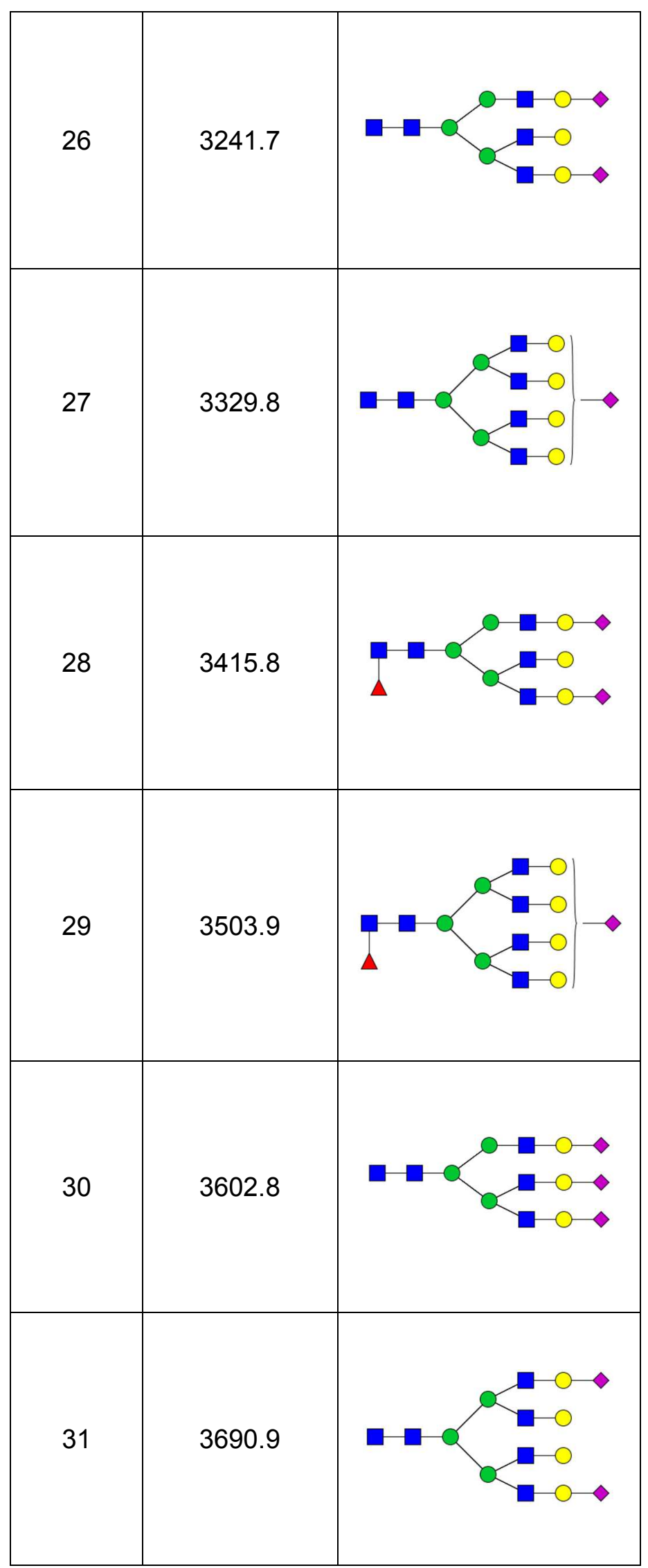




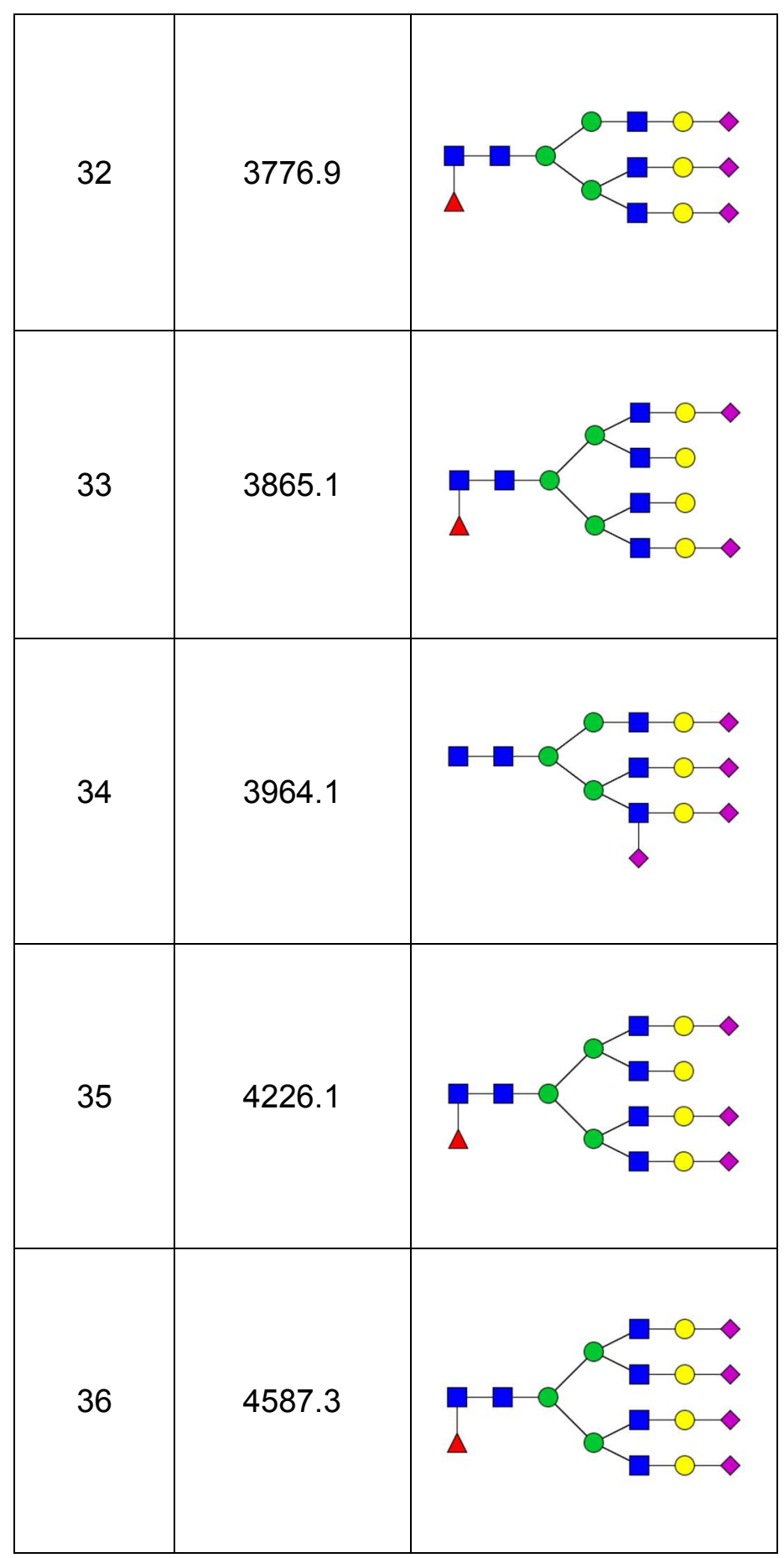

1. Zhou, H., Froehlich, J.W., Briscoe, A.C. \& Lee, R.S. Mol Cell Proteomics 12, 2981-2991 (2013). 
